\title{
Calcarine Artery
}

National Cancer Institute

\section{Source}

National Cancer Institute. Calcarine Artery. NCI Thesaurus. Code C32251.

An artery that branches from the medial occipital artery that aligns with the calcarine sulcus. 